\title{
Cost differentials of dental outpatient care across clinical dentistry branches
}

\author{
Jovana Rančić ${ }^{1}$, Nemanja Rančić ${ }^{2}$, Nemanja Majstorović ${ }^{3}$, Vladimir Biočanin ${ }^{4}$, \\ Marko Milosavljević ${ }^{4}$, Mihajlo Jakovljević ${ }^{5}$ \\ Specialist Dentistry Clinic Dr D. Lopičić, Belgrade, Serbia \\ 2 Centre for Clinical Pharmacology Medical Faculty, Military Medical Academy University of Defence Belgrade, Belgrade, Serbia \\ 3 Jaw orthopedics Clinic, The Faculty of Dentistry University of Belgrade, Serbia \\ ${ }^{4}$ Department of Dentistry The Faculty of Medical Sciences University of Kragujevac, Serbia \\ 5 Department of Pharmacology and Toxicology The Faculty of Medical Sciences University of Kragujevac, Serbia
}

\begin{abstract}
Background: Dental care presents affordability issues in Central \& Eastern European transitional economies due to lack of insurance coverage in most countries of the region and almost complete out-of-pocket payments by citizens. Objective: Real world estimates on cost differentials across clinical dentistry branches, ICD-10 diagnostic groups and groups of dental services. Methods: Prospective case-series cost analysis was conducted from the patient perspective. A six months time horizon was adopted. Sample size was 752 complete episodes of treatment in 250 patients, selected in 2012/2013 throughout several specialist state- and private-owned dental clinics in Serbia. All direct costs of dental care were taken into account and expressed in Euros $(€)$. Results: Mean total costs of dental care were $€ 46 \pm 156$ per single dentist visit while total costs incurred by this population sample were $€ 34,424$. Highest unit utilization of services belongs to conservative dentistry (31.9\%), oral surgery (19.5\%) and radiology (17.4\%), while the resource with the highest monetary value belongs to implantology $€ 828 \pm 392$, orthodontics $€ 706 \pm 667$ and prosthetics $€ 555 \pm 244$. The most frequently treated diagnosis was tooth decay (33.8\% unit services provided), pulpitis (11.2\%) and impacted teeth $(8.5 \%)$, while most expensive to treat were anomalies of tooth position $(€ 648 \pm 667)$, abnormalities of size and form of teeth $(€ 508 \pm 705)$ and loss of teeth due to accident, extraction or local periodontal disease ( $€ 336 \pm 339)$. Conclusion: Although the range of dental costs currently falls behind EU average, Serbia's emerging economy is likely to expand in the long run while market demand for dental services will grow. Due to threatened financial sustainability of current health insurance patterns in Western Balkans, getting acquainted with true size and structure of dental care costs could essentially support informed decision making in future.
\end{abstract}

\section{Keywords}

Health economics, Costs, Dental care

\section{INTRODUCTION}

Global reach of oral health care demand for resources and its need for investment came to public attention mostly in past two decades $[1,2]$. In the European socioeconomic milieu huge budget impact of clinical dentistry was recognized in the early 1990s [3]. It bears particular financial burden for Central \& Eastern European transitional economies due to poor insurance coverage in most countries of the region and huge contribution of outof-pocket payments by ordinary citizens [4]. This is the case with most middle to high-income post-2004 EU members, CIS and Western Balkans countries [5-8].

Dental medicine has extraordinary high demand for services, compared to clinical medicine disciplines mostly due to frequent acute conditions and adverse events of interventions [9-10]. Childhood preventive and conservative dentistry bears particularly sensitive impact in projected long term costs of care [11]. Additional complexity comes to the table with diversity of reimbursement strategies applied on dental care in major markets across the globe [12]. These were occasionally leading to severe disparities in access to dental care as was the case in juvenile population in the US [13-15].

This study presents one of the pioneering attempts in broader Balkan region to assess real costs of these services in the field and describe resource use patterns and differentials across clinical dentistry branches, ICD-10
Corresponding author

Mihajlo (Michael) Jakovljevic, MD, PhD sidartagothama@gmail.com

\section{Disclosure}

The Ministry of Education Science and Technological Development of the Republic of Serbia has funded this study through Grant OI 175014 Publication of results was not contingent to Ministry's censorship or approval. 
diagnostic groups as well as across particular dental services. We have selected the emerging market of Serbia on grounds of being largest Western Balkans market presenting wider regional setting [8]. Its health care sector shares common legacy with most of the region and faces similar challenges in terms of health care provision and financing [16]. Therefore costs and resource use patterns of dental care in Serbia will likely be similar to the ones in neighbour markets as well [17]. According to authors best knowledge so far there have been very few economic analysis on dental care from the South-Eastern European region published in major languages. Authors believe that reliable knowledge on market demand for dentist services and its budget impact across clinical disciplines, might substantially improve informed decision making on resource allocation.

\section{METHODS}

In a prospective case series design, costs analysis has been conducted through the bottom-up approach, adopting the patient perspective and six months time horizon. Sample size was 752 complete episodes of treatment in 250 patients, selected in 2012 and 2013. The institutional framework where services were provided consisted of ten dental facilities in total: five specialist dental clinics belonging to two large traditional state-owned universities and five private-owned dental clinics. University associated facilities were: Childhood and Prevention Dentistry Clinic, Jaw Orthopaedics Clinic, Endodontics and Tooth Disease Clinic, Oral Surgery Clinic belonging to the Faculty of Dentistry Belgrade University, northern Serbia as well as Teaching Clinic of Dentistry Department at The Faculty of Medical Sciences, University of Kragujevac located in central Serbia. Selected private-owned dental clinics were two GP clinics and one specialised in prostetics, located in the capital of Belgrade, and two GP clinics located in the southern Serbian city of Kraljevo. Services were provided by dentist GPs with licence to independent practice, as well as mature specialist dentists. Such choice of target facilities and dentists is justified by eliminating regional variations in routine clinical practice while encompassing three distinct geographic locations within the country [18]. Another aim of such facilities selection was to diminish otherwise relevant impact of ownership structure to clinical decision making [19]. Single episode of treatment included all repeated dentist visits as well as imaging and laboratory diagnostics consumed, related to the key dental condition being the main cause of treatment [20]. These conditions were further stratified and observed through the ICD10 diagnostic codes assigned to them [21]. There were no inclusion criteria limiting the age, sex or medical background heterogeneity of the patients. The only exclusion criteria were people suffering from acute dental conditions requiring emergency care or intensive unit admission within the hospital setting. The purpose of such approach was to provide highest possible diversity of patient sample distribution across clinical disciplines [22].

All data on resource use were acquired via structured questionnaire in Serbian language, filled in by the attending dentists. Survey heading inquired on basic demographics and clinical background, clinical facility in charge and attending dentist background. The rest of the formulary was actually precise and complete list of all dental materials, surgical and imaging diagnostics consumables, pharmaceuticals and implant materials used in routine clinical practice. These lists were occasionally adapted and expanded in specialty clinics due to variety of dental services offered. Each attending dentist together with nursing technician assign to him/her were asked to thoroughly fill in exact amounts of consumables spent and/or frequency of examinations, interventions provided to the particular patient. The same formulary was used for repeated visits by the same patient as long as these where related to treatment of initially diagnosed disorder.

Current official pricelists adopted by The Dentist Chamber of Serbia and clinical facility in charge of each particular episode of treatment, were applied to calculate the costs. Patient diagnosis data were extracted out of patient files and handled anonymously. Data were collected alongside ordinary care without any impact of study protocol to the patterns of routine clinical practice. Due to the fact that patients were not subject to any additional examinations or study - related interventions and were not even interviewed, according to GCP guidelines, study should not be required ethical committee's approval [23].

All direct costs of dental care were taken into account (dentist examinations, radiology imaging and surgical procedures, pharmaceuticals, dental materials and implant acquisition costs etc). Costs were expressed in Euro $(€)$ according to the official exchange course of The National Bank of Serbia in respective years [24].

\section{RESULTS}

Sample size of the study was 752 treatment episodes. There were 250 patients proces- 
sed in 10 clinical facilities. Mean total direct costs of dental care were $€ 46 \pm 156$ per single dentist visit while total costs incurred by this population sample was $€ 34,424$ (Table I). Mean total cost per patient was $€ 138$.

Unit frequency of dentist visits across clinical disciplines were: 240 in Conservative dentistry treatment episodes (31.9\%), 147 in Oral surgery (19.5\%), 131 in Radiology/ Diagnostic Imaging (17.4\%), 82 in Parodontology and Oral Medicine (10.9\%), 72 in Endodontics (9.6\%), 47 in Pediatric and preventive dentistry $(6.3 \%), 19$ in Prosthodontics $(2.5 \%), 11$ in Orthodontics (1.5\%), and 3 in Implantology (0.4\%) (Table I).

\begin{tabular}{|c|c|c|c|c|}
\hline Clinical Dentistry Branch/Discipline & Number (\%) & $€ / p t s(M \pm S D)$ & $95 \% \mathrm{Cl}$ for mean & Total cost $(€)$ \\
\hline Conservative dentistry & $240(31.9)$ & $20 \pm 10$ & $19-21$ & 4,811 \\
\hline Oral surgery & $147(19.5)$ & $24 \pm 38$ & $18-30$ & 3,529 \\
\hline Radiology/Diagnostic Imaging & $131(17.4)$ & $7 \pm 6$ & $6-8$ & 908 \\
\hline Parodontology and oral medicine & $82(10.9)$ & $28 \pm 35$ & $20-36$ & 2,302 \\
\hline Endodontics & $72(9.6)$ & $17 \pm 18$ & $14-20$ & 1,228 \\
\hline Pediatric and preventive dentistry & $47(6.3)$ & $18 \pm 10$ & $15-21$ & 851 \\
\hline Prosthodontics & $19(2.5)$ & $555 \pm 244$ & $437-673$ & 10,549 \\
\hline Orthodontics & $11(1.5)$ & $706 \pm 667$ & $258-1,154$ & 7,761 \\
\hline Implantology & $3(0.4)$ & $828 \pm 392$ & $-147-1,802$ & 2,484 \\
\hline Total & $752(100)$ & $46 \pm 156$ & $35-57$ & 34,424 \\
\hline
\end{tabular}

Table I. Cost matrix - distribution across clinical dentistry branches/disciplines

\begin{tabular}{|c|c|c|c|c|}
\hline ICD-10 Diagnosis groups & $\begin{array}{c}\text { Number } \\
(\%)\end{array}$ & $\begin{array}{c}€ / p t s \\
(M \pm S D)\end{array}$ & $95 \% \mathrm{Cl}$ & $\begin{array}{l}\text { Total cost } \\
\text { (€) }\end{array}$ \\
\hline K05.0 Acute gingivitis & $48(6.4)$ & $19 \pm 7$ & $17-21$ & 910 \\
\hline K05.3 Chronic periodontitis & $57(7.6)$ & $25 \pm 41$ & $14-36$ & 1,424 \\
\hline K02 Dental caries & $254(33.8)$ & $18 \pm 7$ & $17-19$ & 4,521 \\
\hline K01.1 Impacted teeth & $64(8.5)$ & $25 \pm 21$ & $20-30$ & 1,595 \\
\hline Z01.2 Dental examination & $4(0.5)$ & $9 \pm 0$ & $9-9$ & 36 \\
\hline K04.4 Acute apical periodontitis of pulpal origin & $10(1.3)$ & $20 \pm 22$ & $4-36$ & 201 \\
\hline K04.0 Pulpitis & $84(11.2)$ & $14 \pm 9$ & $12-16$ & 1,159 \\
\hline K04.5 Chronic apical periodontitis & $25(3.3)$ & $31 \pm 37$ & $16-47$ & 783 \\
\hline K04.1 Necrosis of pulp & $19(2.5)$ & $19 \pm 44$ & $-2-41$ & 369 \\
\hline K08.1 Loss of teeth due to accident, extraction or local periodontal disease & $31(4.1)$ & $336 \pm 339$ & $212-460$ & 10,415 \\
\hline K03.1 Abrasion of teeth & $1(0.1)$ & $23 \pm 0$ & $0-0$ & 23 \\
\hline S02.5 Fracture of tooth & $21(2.8)$ & $18 \pm 15$ & $11-25$ & 374 \\
\hline K04.7 Periapical abscess without sinus & $4(0.5)$ & $10 \pm 5$ & $2-17$ & 39 \\
\hline K08.3 Retained dental root & $55(7.3)$ & $12 \pm 15$ & $8-16$ & 660 \\
\hline K03.6 Deposits (accretions) on teeth & $4(0.5)$ & $16 \pm 5$ & $9-23$ & 64 \\
\hline Z29.9 Prophylactic measure, unspecified (Fluoride application) & $22(2.9)$ & $17 \pm 10$ & $13-22$ & 380 \\
\hline K05.2 Acute periodontitis & $18(2.4)$ & $11 \pm 7$ & 8-15 & 202 \\
\hline K03.7 Posteruptive colour changes of dental hard tissues & $6(0.8)$ & $61 \pm 37$ & $22-99$ & 365 \\
\hline K10.3 Alveolitis of jaws & $3(0.4)$ & $7 \pm 4$ & $-3-17$ & 21 \\
\hline Q38.1 Ankyloglossia (short frenulum) & $1(0.1)$ & $52 \pm 0$ & $0-0$ & 52 \\
\hline K07.3 Anomalies of tooth position & $12(1.6)$ & $648 \pm 667$ & $224-1,071$ & 7,771 \\
\hline K04.6 Periapical abscess with sinus (Sinus proccidens/tooth in sinus) & $2(0.3)$ & $203 \pm 275$ & $-2,266-2,673$ & 407 \\
\hline K03.1 Abrasion of teeth & $5(0.7)$ & $327 \pm 440$ & $-218-873$ & 1,637 \\
\hline K00.2 Abnormalities of size and form of teeth & $2(0.3)$ & $508 \pm 705$ & $-5,827-6,842$ & 1,015 \\
\hline Total episodes of dental care & $752(100)$ & $46 \pm 156$ & $35-57$ & 34,424 \\
\hline
\end{tabular}

Table II. Costs distribution across episodes of care - most frequent ICD-10 diagnostic entities in clinical practice 
Nevertheless highest cost per patient belongs to other disciplines of clinical dentistry such as Implantology $€ 828 \pm 392$, Jaw Orthopedics $€ 706 \pm 667$, and Protetics $€ 555 \pm 244$ (Table I).

Most frequently treated ICD-10 diagnostic groups in these patients were tooth decay $(33.8 \%$ unit services provided), pulpitis $(11.2 \%)$ and impacted teeth $(8.5 \%)$ (Table
II). Most expensive to treat were some other diagnostic groups such as anomalies of tooth position ( $€ 648 \pm 667$ ), abnormalities of size and form of teeth ( $€ 508 \pm 705)$, and loss of teeth due to accident, extraction or local periodontal disease $(€ 336 \pm 339)$ (Table II). Top most costly treatment methods applied to patients were: fixed braces upper and lower jaw $(€ 1,286 \pm 18)$, surgical implant installa-

\begin{tabular}{|c|c|c|c|c|}
\hline Dentist Medical Service & Number (\%) & $€ / p t s(M \pm S D)$ & $95 \% \mathrm{Cl}$ & Total cost $(€)$ \\
\hline Ultrasonic descaling and removal of soft deposits & $64(8.5)$ & $19 \pm 7$ & $17-21$ & 1,217 \\
\hline Removal of soft deposits & $2(0.3)$ & $14 \pm 6$ & $-44-72$ & 27 \\
\hline Treatment of periodontal pockets & $12(1.6)$ & $49 \pm 47$ & $19-79$ & 590 \\
\hline Composite in posterior teeth & $176(23.4)$ & $20 \pm 6$ & $19-21$ & 3,481 \\
\hline Surgical extraction of impacted wisdom teeth & $38(5.1)$ & $30 \pm 16$ & 25-35 & 1,141 \\
\hline OPT footage & $67(8.9)$ & $10 \pm 6$ & $8-11$ & 658 \\
\hline RTG footage & $73(9.7)$ & $4 \pm 2$ & $4-5$ & 328 \\
\hline Therapy of deep cavities without fillings & $10(1.3)$ & $10 \pm 1$ & $9-11$ & 98 \\
\hline Composite in anterior teeth & $42(5.6)$ & $17 \pm 4$ & $16-19$ & 729 \\
\hline Endodontic therapy infected pulp & $8(1.1)$ & $28 \pm 21$ & $10-46$ & 224 \\
\hline Endodontic therapy uninfected pulp & $33(4.4)$ & $21 \pm 11$ & $17-24$ & 682 \\
\hline Local application of the drug - Toxavit ${ }^{\circledR}$ & $22(2.9)$ & $11 \pm 4$ & $10-13$ & 251 \\
\hline Application of medicament between sessions & $8(1.1)$ & $9 \pm 1$ & $9-10$ & 75 \\
\hline Abscess drainage and irrigation & $5(0.7)$ & $7 \pm 4$ & $2-12$ & 34 \\
\hline Surgical implant installation & $3(0.4)$ & $828 \pm 392$ & $-147-1,802$ & 2,484 \\
\hline Extraction of milk teeth & $3(0.4)$ & $9 \pm 0$ & $9-9$ & 27 \\
\hline Extraction of permanent teeth & $58(7.7)$ & $13 \pm 6$ & $11-14$ & 743 \\
\hline Glass ionomer restorative & $9(1.2)$ & $20 \pm 6$ & $16-25$ & 182 \\
\hline Trial test vitality & $1(0.1)$ & $5 \pm 0$ & $0-0$ & 5 \\
\hline Upgrade fractured tooth-composite & $3(0.4)$ & $36 \pm 16$ & $-3-76$ & 109 \\
\hline Sealing of dental fissures & $20(2.7)$ & $17 \pm 11$ & $12-22$ & 344 \\
\hline Extraction of residual root & $39(5.2)$ & $14 \pm 17$ & $9-20$ & 549 \\
\hline Fluoridation of teeth (local application of fluoride) & $2(0.3)$ & $18 \pm 0$ & $18-18$ & 36 \\
\hline Resection of the root canal obturation with orthograde & $10(1.3)$ & $64 \pm 40$ & $35-92$ & 637 \\
\hline Surgical removal of tooth & $2(0.3)$ & $56 \pm 39$ & $-293-406$ & 113 \\
\hline Outpatient teeth whitening & $3(0.4)$ & $94 \pm 5$ & $81-107$ & 283 \\
\hline Surgical release of impacted canine teeth & $2(0.3)$ & $87 \pm 5$ & $40-135$ & 175 \\
\hline Curettage of inflamed tooth cup after tooth extraction & $2(0.3)$ & $9 \pm 0$ & $9-9$ & 18 \\
\hline Upgrading the treated endodontic tooth using dental poles & $3(0.4)$ & $33 \pm 12$ & $3-62$ & 98 \\
\hline Veneers & $4(0.5)$ & $27 \pm 0$ & $27-27$ & 109 \\
\hline Flap surgery & $1(0.1)$ & $262 \pm 0$ & $0-0$ & 262 \\
\hline Frenectomio & $1(0.1)$ & $52 \pm 0$ & $0-0$ & 52 \\
\hline Fixed braces upper and lower jaw & $6(0.8)$ & $1286 \pm 18$ & $1,267-1,305$ & 7,716 \\
\hline Sinus lift and artificial bone & $1(0.1)$ & $398 \pm 0$ & $0-0$ & 398 \\
\hline Metal-ceramic crowns cast + upgrade & $2(0.3)$ & $533 \pm 470$ & $-3,693-4,759$ & 1,066 \\
\hline Metal-ceramic crowns & $5(0.7)$ & $753 \pm 250$ & $443-1,063$ & 3,764 \\
\hline Upper and lower denture & $6(0.8)$ & $441 \pm 5$ & $436-446$ & 2,645 \\
\hline Two partial acrylic dentures & $1(0.1)$ & $447 \pm 0$ & $0-0$ & 447 \\
\hline Two partial skeleton dentures & $3(0.4)$ & $730 \pm 0$ & $730-730$ & 2,189 \\
\hline Upper and lower total denture & $1(0.1)$ & $219 \pm 0$ & $0-0$ & 219 \\
\hline Upper and lower partial acrylic dentures & $1(0.1)$ & $219 \pm 0$ & $0-0$ & 219 \\
\hline Total & $752(100)$ & $46 \pm 156$ & $35-57$ & 34,424 \\
\hline
\end{tabular}

Table III. Costs distribution across most frequent dentist services in clinical practice 
tion $(€ 828 \pm 392)$, metal-ceramic crowns $(€$ $753 \pm 250)$, two partial skeleton dentures $(€$ $730 \pm 0)$, metal-ceramic crowns cast + upgrade $(€ 533 \pm 470)$, two partial acrylic dentures (€ $447 \pm 0)$, upper and lower denture (€ 441 \pm 5 ), sinus lift and artificial bone $(€ 398 \pm$ $0)$, flap surgery (€ $262 \pm 0)$, upper and lower total denture $(€ 219 \pm 0)$, and upper and lower partial acrylic dentures (€ $219 \pm 0$ ) (Table III).

An in depth cost data related to ICD-10 diagnostic codes of conditions treated as well as across particular dental services offered, are presented in the Tables I-III.

\section{DISCUSSION}

According to official release by the Republican Health Insurance Fund in Serbia, public expenditure on dental services has been decreasing mostly steadily from $€ 51,131,383$ in 2007 to $€ 41,505,573$ in 2012 (latest accessible release) [25]. As opposed to this trend, during the same period of time overall public expenditure on health has slightly increased from $€ 1,813,552,586$ in 2007 to $€$ $1,847,971,776$ in 2012 but essentially reaching plateau level [26]. Decrease of public expenditure on dentistry services that happened across six years time span was almost $19 \%$. We should be aware that this change happened during period when total healthcare spending in the country remained stable or exhibited slow growth pattern $[8,16]$. Opposed trend of public spending on health care services is certainly not following oral diseases incidences which are not optimistic particularly with regards to huge prevalence pool of common tooth decay, paradontosis, and associated conditions [27]. Market demand for these services is likely to remain strong in this area in the long term as well [28]. The essential issue that arises is difficulty of access to dentist's services because of rather limited affordability to the common citizens because of reliance to out-of-pocket financing [29-31]. This will particularly be the case with more demanding conditions to treat requesting surgical approach or implanting permanent artificial teeth supporting structures [32]. Expected consequence of neglected oral health is likely tooth loss [33]. Clinical risk of spreading of late recognized and mistreated infection to the neighbouring soft tissues presents the issue of its own [34]. Furthermore, much anticipated consequence of authorities' lack of attention to this field of clinical medicine, is the so called boomerang effect. Low-income society members who were initially denied preventive and primary care services will ultimately end up as an inpatients suffering from severe dental conditions originating from these simple initial diagnosis [35-37]. As was the case with our patient sample, most frequent clinical conditions were tooth decay, pulpitis and impacted teeth in decreasing order of appearance. At that stage, they will likely consume substantial value of laboratory and imaging diagnostics and need oral surgery and anesthesiology specialist services as well as more nursing care [38]. This was exactly the case with the most expensive treatment episodes noticed in this study such as implantology, jaw orthopedics and protetics cases. In line with this highest unit utilization of services in our sample belonged to disciplines of conservative dentistry, oral surgery and radiology. These ultimately hospital services for the inpatients, according to the local legislative and funding framework will have to be reimbursed. Some of the most expensive conditions to treat we observed were anomalies of tooth position, abnormalities of size and form of teeth and loss of teeth due to accident, extraction or local periodontal disease. Significant opportunity costs such as patient's lost productivity, absenteeism and decreased quality of life are obvious consequences of such funding policy [39-40].

\section{Limitations}

Variety of dental general and specialty care facilities were selected in order to have a balanced representation of public and private dental sector in Serbia. Nevertheless sample size remains rather small. This was the case because dentists' compliance in academic non-sponsored research in the region is rather low as well as due to budget constraints of the study. Nevertheless study does not attempt to generalize its findings to the national level but to point out deep differences in budget impact of certain clinical disciplines. Patient selection leans towards more clinical (treatment) group rather than visiting patterns of the general population. Therefore we may assume that our results are thus rather more indicative of costs of dental care for patients suffering from more severe disorders. Future research on dental health economics should target broader patient population in Western Balkans region while providing far more ambitious insight into clinical course of illness related to resource use and costs of care.

\section{CONCLUSIONS}

Dental care bears particular financial burden for Western Balkan transitional economies due to its lack of insurance coverage in most countries of the region and almost complete 
out-of-pocket payments by citizens. Extraordinary high demand for services, compared to most clinical medicine branches, frequent acute conditions and adverse events contribute to this burden. Although range of these costs currently falls behind EU average, Serbia's emerging economy is likely to expand in the long run while market demand for dentist services will grow. Additional obstacle to provision of accessible dental care is current trend in public expenditure on dentistry decreasing one-fifth in 2007-2012 time span.
This fact bears particular weight because total public expenditure on health remained rather stable during this time. Rather serious societal investment into preventive dentistry would highly likely yield long term fruits for the community both in terms of oral health and cost savings [41-43]. Due to threatened financial sustainability of current health insurance patterns in Western Balkans, knowledge on true size and fine structure of dental care costs could essentially support evidence based resource allocation in future.

\section{REFERENCES}

1. Petersen PE. The World Oral Health Report 2003: continuous improvement of oral health in the 21st century-the approach of the WHO Global Oral Health Programme. Community Dent Oral Epidemiol 2003; 31: 3-24; http:// dx.doi.org/10.1046/j..2003.com122.x

2. Petersen PE, Bourgeois D, Ogawa H, et al. The global burden of oral diseases and risks to oral health. Bulletin of the World Health Organization 2005 83: 661-9

3. Abel-Smith B, Mossialos E. Cost containment and health care reform: a study of the European Union. Health Policy 1994; 28: 89-132; http://dx.doi.org/10.1016/0168-8510(94)90030-2

4. Lewis M. Informal payments and the financing of health care in developing and transition countries. Health Aff (Millwood) 2007; 26: 984-97; http://dx.doi.org/10.1377/hlthaff.26.4.984

5. Falkingham, J. Poverty, out-of-pocket payments and access to health care: evidence from Tajikistan. Soc Sci Med 2004; 58: 247-58; http://dx.doi.org/10.1016/S0277-9536(03)00008-X

6. Belli P, Gotsadze G, Shahriari H. Out-of-pocket and informal payments in health sector: evidence from Georgia. Health Policy 2004; 70: 109-23; http://dx.doi.org/10.1016/j.healthpol.2004.03.007

7. Delcheva E, Balabanova D, McKee M. Under-the-counter payments for health care: evidence from Bulgaria. Health policy 1997; 42: 89-100; http://dx.doi.org/10.1016/S0168-8510(97)00061-4

8. Jakovljević M, Jovanović M, Lazić Z, et al. Current efforts and proposals to reduce healthcare costs in Serbia. SJECR 2011; 12: 161-3

9. Kim H, Ahn E, Kim M, et al. Trends of household income and dental care spending. J Korean Acad Oral Health 2014; 38: 17-24; http://dx.doi.org/10.11149/jkaoh.2014.38.1.17

10. Nihtilä A. Heavy use of oral health services. Helsinki: University of Helsinki, 2014. Available at: http://urn.fi/ URN:ISBN:978-952-10-9815-4 (last accessed May 2014)

11. Petersen PE. Changing oral health profiles of children in Central and Eastern Europe - Challenges for the 21st century. WHO, 2003. Available at: http://www.who.int/oral_health/publications/icd01/en/(last accessed May 2014)

12. Feinstein-Winitzer RT, Pollack HA, Parish CL, et al. Insurer Views on Reimbursement of Preventive Services in the Dental Setting: Results From a Qualitative Study. Am J Public Health 2014; 104: 881-7; http://dx.doi.org/10.2105/ AJPH.2013.301825

13. Edelstein BL. Disparities in oral health and access to care: findings of national surveys. Ambul Pediatr 2002; 2 : 141-7; http://dx.doi.org/10.1367/1539-4409(2002)002<0141:DIOHAA>2.0.CO;2

14. Mofidi M, Rozier RG, King RS. Problems with access to dental care for Medicaid-insured children: what caregivers think. Am J Public Health 2002; 92: 53-8; http://dx.doi.org/10.2105/AJPH.92.1.53

15. Liu J, Probst JC, Martin AB, et al. Disparities in dental insurance coverage and dental care among US children: the National Survey of Children's Health. Pediatrics 2007; 119 Suppl 1: 12-21; http://dx.doi.org/10.1542/peds.20062089D

16. Jakovljevic MB. Resource allocation strategies in South-Eastern European health policy. Eur J Health Econ 2013; 14: 153-9; http://dx.doi.org/10.1007/s10198-012-0439-y

17. Katrova L, Tzokov K. Demography and market impacts on dental practices' development in Bulgaria during the period of transition 1990-2010. Acta Med Acad 2013; 42: 229; http://dx.doi.org/10.5644/ama2006-124.91 
18. Fisher ES, Bynum JP, Skinner JS. Slowing the growth of health care costs - lessons from regional variation. $N$ Engl J Med 2009 360: 849-52; http://dx.doi.org/10.1056/NEJMp0809794

19. Schlesinger M, Cleary PD, Blumenthal D. The ownership of health facilities and clinical decisionmaking: the case of the ESRD industry. Med Care 1989; 27: 244-58; http://dx.doi.org/10.1097/00005650-198903000-00003

20. Keeler EB, Rolph JE. The demand for episodes of treatment in the health insurance experiment. $J$ Health Econ 1988; 7: 337-67; http://dx.doi.org/10.1016/0167-6296(88)90021-5

21. The Web's Free 2014 ICD-10-CM and ICD-10-PCS Medical Coding Reference. 2014 ICD-10-CM Codes. Available at: http://www.icd10data.com/ICD10CM/Codes (last accessed May 2014)

22. Groot Koerkamp B, Weinstein M C, Stijnen T, et al. Uncertainty and patient heterogeneity in medical decision models. Med Decis Making 2010 30: 194-205; http://dx.doi.org/10.1177/0272989X09342277

23. Rikkert M G, Lauque S, Frölich L, et al. The practice of obtaining approval from medical research ethics committees: a comparison within 12 European countries for a descriptive study on acetylcholinesterase inhibitors in Alzheimer's dementia. Eur J Neurol 2005 12: 212-217; http://dx.doi.org/10.1111/j.1468-1331.2004.00980.x

24. Josifidis K, Allegret JP, Pucar EB. Monetary and Exchange Rate Regimes Changes: The Cases of Poland, Czech Republic, Slovakia and Republic of Serbia. Panoeconomicus 2009; 56: 199-226

25. National Health Insurance Fund. Annual financial reports, 2013. Available from: http://www.rfzo.rs/index.php/ finansijski/fin-izvestaji (last accessed May 2014)

26. Jakovljevic MB. Oncology monoclonal antibodies expenditure trends and reimbursement projections in the emerging Balkan market. Farmeconomia. Health economics and therapeutic pathways 2014; 15: 27-32; http://dx.doi. org/10.7175/fe.v15i1.909

27. Janjanin, M. Program of oral health as a part of the public health program in Republic Serbia. Med Arh 2000; 55: 29-30

28. Bredenkamp C, Gragnolati M. Sustainability of Healthcare Financing in the Western Balkans: an Overview Of Progress and Challenges. World Bank Publications, 2007

29. Wallace B, Figueiredo R, MacEntee MI, et al. Homelessness and oral health. In Guirguis-Younge M, Hwang S, McNeil R. (Eds.) Homelessness and Health in Canada. Ottawa: University of Ottawa Press, 2012

30. Gharibi F, Heidari A, Zarei M. Percentage of out-of-pocket payment for health services by people of Kurdistan in 2010. Sci J Kurdistan Univ Med Sci 2013; 18: 20-8

31. Cruz GD. Oral health disparities: Opportunities and challenges for policy communication. Journal of Communication in Healthcare Strategies, Media and Engagement in Global Health 2014; 7: 74-6

32. Harikumar K, Nandakumar K, Devadas C, et al. Collagen-Chitosan barrier membrane, a novel, indigenous, and economic material for management of periodontal infrabony defects-A case-Control Study. Univ Res J Dent 2014; 4: $87-92$

33. Rousseau N, Steele J, May C, et al. Your whole life is lived through your teeth: biographical disruption and experiences of tooth loss and replacement. Sociol Health Ill. 2013; 36: 462-6

34. Albandar JM. Aggressive and acute periodontal diseases. Periodontol 2000 2014; 65: 7-12; http://dx.doi.org/10.1111/ prd.12013

35. Melton L. Effects of information sharing between inpatient and outpatient healthcare providers on length of postdischarge office visit. Lehigh County: DeSales University, 2013

36. Richard P, Shin P, Vasilkovska K, et al. Bending the Health Care Cost Curve in North Carolina: The Experience of Community Health Centers. Geiger Gibson/ RCH Community Health Foundation Research Collaborative. Policy Research Brief \#24. The George Washington University, 2011. Available at: http://www.rchnfoundation.org/?p=899 (last accessed May 2014]

37. Sundberg T, Petzold M, Kohls N, et al. Opposite Drug Prescription and Cost Trajectories following Integrative and Conventional Care for Pain-A Case-Control Study. PloS One 2014; 9: e96717; http://dx.doi.org/10.1371/journal. pone. 0096717

38. Kim MY, Choi HN, Shin HS. Dental implant bottom-up cost analysis. J Korean Acad Prosthodont 2014; 52: 18-26; http://dx.doi.org/10.4047/jkap.2014.52.1.18

39. Litaker MS. Self-reported measures may be useful in surveillance for periodontitis. J Evid Based Dent Pract 2014; 14: 67-9; http://dx.doi.org/10.1016/j.jebdp.2014.04.020

40. Samsonyanová L, Broukal Z. A Systematic Review of Individual Motivational Factors in Orthodontic Treatment: Facial Attractiveness as the Main Motivational Factor in Orthodontic Treatment. Int J Dent 2014; 2014: 938274 ; http://dx.doi.org/10.1155/2014/938274 
41. Mehta A, Sehgal P, Singla YK. An overview of oral health promotion and its effectiveness in prevention of oral diseases. BFUDJ 2013; 4: 56-60

42. Gould IM, Buckingham JK. Cost effectiveness of prophylaxis in dental practice to prevent infective endocarditis. Br Heart J 1993; 70: 79-83; http://dx.doi.org/10.1136/hrt.70.1.79

43. Lee JY, Bouwens TJ, Savage MF, et al. Examining the cost-effectiveness of early dental visits. Pediatr Dent 2006; 28: 102-5 